\title{
Inhibition of microRNA-25 by tumor necrosis factor $\alpha$ is critical in the modulation of vascular smooth muscle cell proliferation
}

\author{
LICHUN QI, JIXIN ZHI, TONG ZHANG，XUE CAO，LIXIU SUN，YUANYUAN XU and XUEQI LI \\ Cardiovascular Department, The Fourth Affiliated Hospital, Harbin Medical University, \\ Harbin, Heilongjiang 150001, P.R. China
}

Received August 27, 2014; Accepted December 19, 2014

DOI: $10.3892 / \mathrm{mmr} .2015 .3329$

\begin{abstract}
Atherosclerosis and coronary heart disease are characterized by a hyperplastic neointima and inflammation involving cytokines, such as tumor necrosis factor- $\alpha$ (TNF- $\alpha$ ). TNF- $\alpha$ is pleiotropic and mediates inflammation and proliferation in various cell types, such as vascular smooth muscle cells (VSMCs). The molecular mechanism for the pleiotropic effects of TNF- $\alpha$ has not previously been fully elucidated. The current study identified that the expression of microRNA-25 (miR-25), a small noncoding RNA, was reduced in response to TNF- $\alpha$ signaling in VSMCs. Restored miR-25 expression inhibited cell proliferation and $\mathrm{Ki}-67$ expression. The present study indicated that cyclin-dependent kinase 6 (CDK6) was the direct target gene of miR-25 using mRNA and protein expression analysis, and luciferase assays. It was also observed that restored CDK6 expression in the miR-25 mimic-treated VSMCs partly reduced miR-25-mediated VSMC proliferation. In conclusion, miR-25 is suggested to be important in TNF- $\alpha$-induced abnormal proliferation of VSMCs.
\end{abstract}

\section{Introduction}

The vasculature is predominantly comprised of vascular smooth muscle cells (VSMCs), and these cells are involved in the maintenance of vessel tone and blood pressure $(1,2)$. Abnormal proliferation of VSMCs is key in the pathogenesis of cardiovascular diseases, such as coronary heart disease, hypertension and atherosclerosis $(3,4)$. Several growth factors and cytokines have been reported to be capable of stimulating the migration and proliferation of VSMCs, for example leptin, which is vital in restenosis (5-7). A previous study indicated that tumor necrosis factor- $\alpha(\mathrm{TNF}-\alpha)$ is a major risk factor in atherosclerosis and coronary heart disease (8). TNF- $\alpha$ is

Correspondence to: Professor Xueqi Li, Cardiovascular Department, The Fourth Affiliated Hospital, Harbin Medical University, 31 Yinhang Street, Harbin, Heilongjiang 150001, P.R. China

E-mail: qilichun1@yeah.net

Key words: atherosclerosis, tumor necrosis factor- $\alpha$, microRNA, microRNA-25, proliferation a pleiotropic inflammatory cytokine that has been reported to serve a pathophysiological role in vascular atherosclerosis $(9,10)$. In addition, TNF- $\alpha$ has been demonstrated to regulate the proliferation, apoptosis, migration and differentiation of VSMCs, which are critical in the pathogenesis of cardiovascular disease $(8,11,12)$. However, the precise mechanism underlying TNF- $\alpha$-induced proliferation of VSMCs remains to be fully elucidated.

MicroRNAs (miRNAs) are a class of small (22-nucleotide) noncoding RNA molecules that function as endogenous silencers of various target genes (13-15). The majority of mature miRNAs suppress gene expression either by facilitating the cleavage of their target messenger RNAs (mRNAs) or by inhibiting mRNA translation upon imperfect base pairing to the 3'-untranslated region (3'-UTR) of the mRNA $(16,17)$. It has been reported that miRNAs are highly conserved among species and are crucial in various physiological and pathological processes, including age-associated diseases, developmental abnormalities, autoimmune diseases and various types of cancer (18-21). The role of miRNAs in the cardiovascular system has been previously investigated $(22,23)$; however, the function of miRNAs in the proliferation of VSMCs induced by TNF- $\alpha$ remains to be fully investigated.

In the current study, it was hypothesized that the expression of miR-25 was inhibited in TNF- $\alpha$-stimulated VSMCs and that overexpression of miR-25 in the VSMCs inhibited cell proliferation by targeting cyclin-dependent kinase 6 (CDK6). Thus, the current study aimed to elucidate whether miR-25 was impaired in the pathogenesis of atherosclerosis and coronary heart disease, and may be a potential therapeutic target in atherosclerosis and coronary heart disease.

\section{Materials and methods}

Ethical statement. All experiments were approved by the Clinical Research Ethics Committee of The Fourth Affiliated Hospital, Harbin Medical University (Harbin, China).

Vectors and cell culture. The pcDNA-CDK6 vector was purchased from Sigma-Aldrich (Oakville, ON, Canada). The CDK6 3'UTR sequence with the binding site for miR-25 was cloned into the pMIR-REPORT luciferase construct (Ambion Life Technologies, Carlsbad, CA, USA). The 
mutant construct of CDK6 3'UTR was generated using the QuikChange Site-Directed Mutagenesis kit (Agilent Technologies, Inc., Santa Clara, CA, USA). The reagents for cell culture (fetal bovine serum, penicillin and streptomycin) were purchased from Gibco Life Technologies (Carlsbad, CA, USA). Human VSMCs were obtained from the American Type Culture Collection (Manassas, VA, USA) and cultured in the medium 231 supplemented with smooth muscle cell growth supplement (Gibco Life Technologies) at $37^{\circ} \mathrm{C}$ in a humidified atmosphere of $95 \%$ air and $5 \% \mathrm{CO}_{2}$.

Cell transfection. The miR-25 mimics and the control were synthesized by Shanghai GenePharma Co., Ltd. (Shanghai, China) and transfected into the cells to a final oligonucleotide concentration of $20 \mathrm{nmol} / \mathrm{l}$. All cell transfections were introduced using DharmaFECT 1 reagent (GE Healthcare Biosciences, Pittsburgh, PA, USA) according to the manufacturer's instructions.

RNA isolation and reverse transcription-quantitative polymerase chain reaction ( $R T-q P C R)$. Total RNA was isolated using TRIzol reagent (Invitrogen Life Technologies, Carlsbad, CA, USA) and the miRNA was reverse transcribed into cDNA (miRNA reverse kit, Promega Corp., Madison, WI, USA). The reaction mixture contained $1 \mu \mathrm{g}$ purified total RNA, 5X M-MLV buffer (Invitrogen Life Technologies), $200 \mathrm{U} / \mu 1$ (M-MLV; Invitrogen Life Technologies), $1.0 \mu \mathrm{l}$ dithiothreitol (Invitrogen Life Technologies), $1.0 \mu \mathrm{l}$ of $10 \mu \mathrm{mol} / 1$ stem-loop RT primer (Invitrogen Life Technologies), $0.5 \mu 1$ of $40 \mathrm{U} / \mu 1$ RNase inhibitor (Invitrogen Life Technologies) and $1.0 \mu \mathrm{l}$ of $10 \mathrm{mmol} / \mathrm{l}$ deoxyribonucleotide triphosphate (Invitrogen Life Technologies). Relative transcript levels of mRNA were determined by RT-qPCR using the ABI 7300 Real-time PCR system (Applied Biosystems Life Technologies, Foster City, CA, USA). The RT-qPCR reaction was composed of 1 X SYBR green fluorescent dye (Takara Biotechnology Co., Ltd., Dalian, China), $1 \mu \mathrm{l}$ of $10 \mu \mathrm{M}$ forward primers, $1 \mu \mathrm{l}$ of $10 \mu \mathrm{M}$ reverse primers, 1X qPCR mix (Invitrogen Life Technologies) and $1 \mu 1$ cDNA. Reactions were run with the following thermal cycling parameters: $95^{\circ} \mathrm{C}$ for $5 \mathrm{~min}$ followed by 35 cycles of $95^{\circ} \mathrm{C}$ for $5 \mathrm{sec}$ and $60^{\circ} \mathrm{C}$ for $30 \mathrm{sec}$; melting curve program $\left(60-95^{\circ} \mathrm{C}\right)$ with a heating rate of $0.1^{\circ} \mathrm{C} / \mathrm{sec}$. The relative gene expression was assessed by the $\Delta \Delta \mathrm{Ct}$ method. GAPDH or U6 was used as an internal control (Table I).

Cell proliferation assays. Cells were seeded in 96-well plates at a density of 1,000 cells/well with $100 \mu \mathrm{l}$ complete culture medium. The cells were then cultured for an additional 24,48 or $72 \mathrm{~h}$. The supernatant was removed and $100 \mu \mathrm{l}$ medium 231 containing $10 \mu \mathrm{l}$ Cell Counting kit 8 (CCK-8; Dojindo Molecular Technologies, Inc., Kumamoto, Japan) was added to each well for a $2-\mathrm{h}$ incubation at $37^{\circ} \mathrm{C}$. The culture plates were then agitated for $10 \mathrm{~min}$ and the optical density values were read at a wavelength of $450 \mathrm{~nm}$ using a Thermo Fisher Scientific microplate reader (Beijing, China).

Dual luciferase assays. Cells were co-transfected with $0.4 \mu \mathrm{g}$ miR-25 or negative controls and the reporter construct $0.2 \mu \mathrm{g}$ pGL-3 control vector (Promega Corp.). Cells were plated at a density of $5 \times 10^{5}$ cells/well in 24 -well plates $24 \mathrm{~h}$ prior to transfection. The cells were harvested $24 \mathrm{~h}$ post-transfection and assayed using the Dual-Luciferase Reporter Assay system (Promega Corp.) according to manufacturer's instructions. Firefly luciferase values were normalized to Renilla and the ratio of Firefly/Renilla luciferase values was reported.

Western blotting. Total cellular protein extraction and western blotting procedures were conducted using standard methods (14). CDK-6 and GAPDH proteins were incubated with rat polyclonal anti-human CDK-6 (1:1,000; Abcam, Cambridge, UK) and mouse polyclonal anti-human GAPDH (1:5,000: ProteinTech Group, Inc., Chicago, IL, USA) primary antibodies, respectively. The membranes were subsequently incubated with horseradish peroxidase-labeled rabbit anti-mouse and goat anti-rabbit antibodies (ZSGB-BIO, Beijing, China). the signal was detected using an enhanced chemiluminescence kit (EMD Millipore, Billerica, MA, USA).

Statistical analysis. Each experiment was repeated a minimum of three times. Statistical analysis was performed using SPSS, version 15.0 (SPSS, Inc., Chicago, IL, USA). Data are presented as the mean \pm standard deviation. Either the analysis of variance or Student's t-test was completed in order to analyze the data and $\mathrm{P}<0.05$ (two-tailed) was considered to indicate a statistically significant difference.

\section{Results}

Expression of miR-25 is reduced in VSMCs induced by TNF- $\alpha$. A significant time-dependent induction of cell proliferation by TNF- $\alpha(100 \mathrm{ng} / \mathrm{ml})$ was observed with the maximal response at $72 \mathrm{~h}(\mathrm{P}<0.001)$ using the CCK-8 proliferation assay (Fig. 1A). Inhibition of miR-25 expression was observed in VSMCs following TNF- $\alpha$ stimulation with RT-qPCR analysis (Fig. 1B).

Overexpression of miR-25 inhibits VSMC proliferation. VSMCs were transfected with miR-25 mimics or control oligo, which were demonstrated to have high transfection efficiency (Fig. 2A; P<0.001). The CCK-8 proliferation assay indicated that cell proliferation was significantly decreased in miR-25 mimic-transfected VSMCs compared with the control oligo-transfected cells or untreated cells (Fig. 2B). This proliferative effect of miR-25 was further confirmed by Ki-67 expression. As demonstrated in Fig. 2C, a significant decrease in the protein expression of $\mathrm{Ki}-67$ was observed in the group transfected with miR-25 mimics as compared with the control group or untreated group.

miR-25 directly regulates the CDK6 gene in VSMCs. The current study suggested CDK6 as a potential target of miR-25 (Fig. 3A). To confirm whether CDK6 is a target, luciferase reporter gene assays were conducted. The miR-25 mimic rather than control significantly suppressed the luciferase activity of the reporter gene containing wild-type 3'-UTR of CDK6 $(\mathrm{P}<0.001)$; however, did not affect the activity of the gene containing the mutant 3'-UTR (Fig. 3B). Furthermore, the mRNA and protein levels of CDK6 were detected following transfection of cells with the miR-25 mimic. Notably, mRNA and protein levels of CDK6 were substantially reduced upon transfection with the miR-25 mimic (Fig. 3C and D; $\mathrm{P}<0.001$ ). 
Table I. Primer sequences.

Primer

Sequence $\left(5^{\prime}-3^{\prime}\right)$

MicroRNA reverse transcription primer

MicroRNA-25

GTCGTATCCAGTGCGTGTCGTGGAGTCG

U6 snRNA

GCAATTGCACTGGATACGACTCAGAC

Real-time polymerase chain reaction primer sequence

MicroRNA-25

AAAATATGGAACGCTTCACGAATTTG

U6 snRNA

F: CATTGCACTTGTCTCGGTCTG

R: ATTGCGTGTCGTGGAGTCG

F: CTCGCTTCGGCAGCACATATACT

R: ACGCTTCACGAATTTGCGTGTC

GAPDH

F: AATGGGCAGCCGTTAGGAAA

Ki-67

R: TGAAGGGGTCATTGATGGCA

CDK6

F: TCCTTTGGTGGGCACCTAAGACCTG

R: TGATGGTTGAGGTCGTTCCTTGATG

F: GGACTTTCTTCATTCACACCG

R: GACCACTGAGGTTAGGCCA

F, forward; R, reverse; snRNA, small nuclear RNA.

A

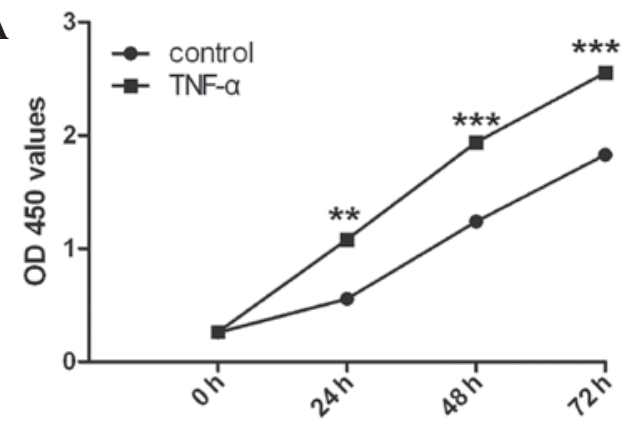

B

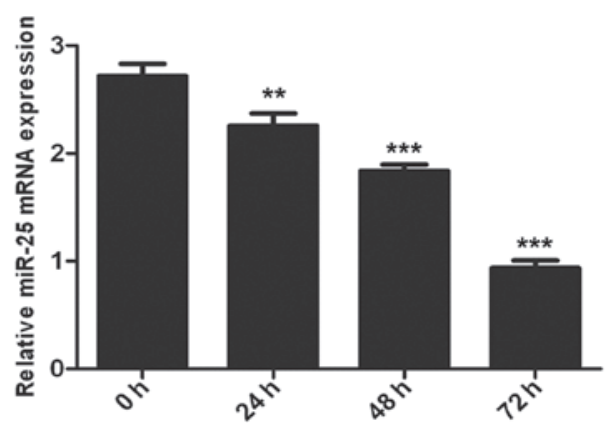

Figure 1. Expression of miR-25 is reduced in VSMCs induced by TNF- $\alpha$. (A) The Cell Counting kit- 8 proliferation assay demonstrated that TNF- $\alpha$ (100 ng/ml) can promote VSMC proliferation. (B) Reverse transcription-quantitative polymerase chain reaction analysis demonstrated that TNF- $\alpha$ can inhibit the expression of miR-25. ${ }^{* *} \mathrm{P}<0.01$ and ${ }^{* * * *} \mathrm{P}<0.001$ vs. control. miR-25, microRNA-25; VSMCs, vascular smooth muscle cells; TNF- $\alpha$, tumor necrosis factor- $\alpha$; OD, optical density.

A

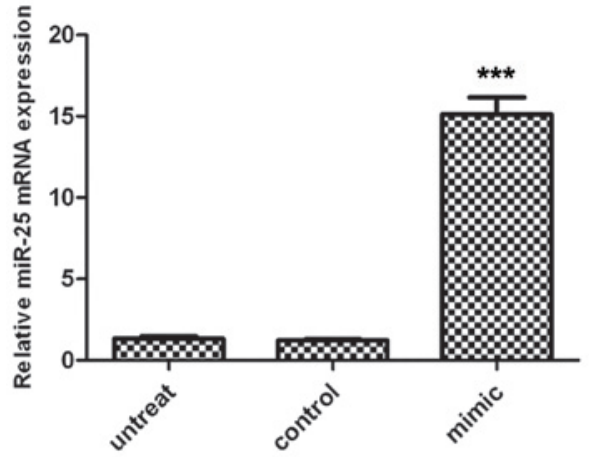

B

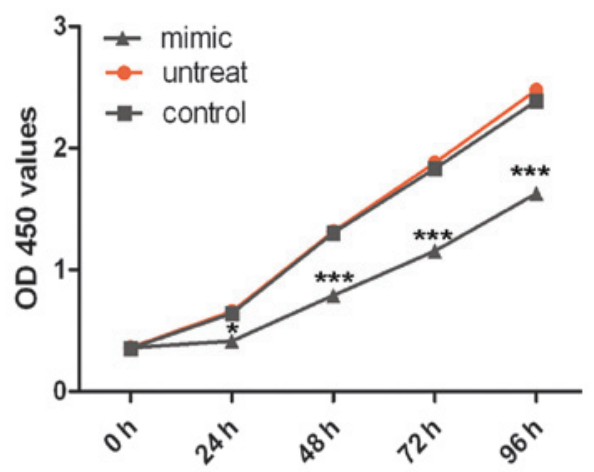

C

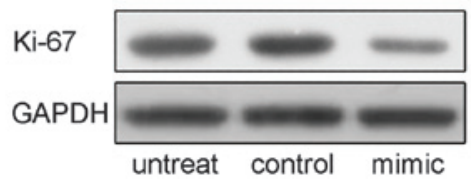

Figure 2. Overexpression of miR-25 inhibits VSMC proliferation. (A) The expression levels of miR-25 were examined following transfection of miR-25 mimics or control or no transfection using reverse transcription-quantitative polymerase chain reaction. (B) The Cell Counting kit-8 proliferation assay demonstrated that the miR-25 mimic was able to inhibit the proliferation of VSMCs. (C) Western blot analysis demonstrated that overexpression of miR-25 inhibited the protein expression of Ki-67. GAPDH was also detected as a loading control. ${ }^{*} \mathrm{P}<0.05$ and ${ }^{* * *} \mathrm{P}<0.001$ vs. control. miR-25, microRNA-25; VSMC, vascular smooth muscle cells; OD, optical density; untreat, untreated. 
A

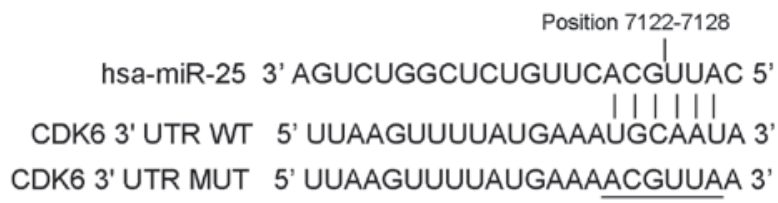

B

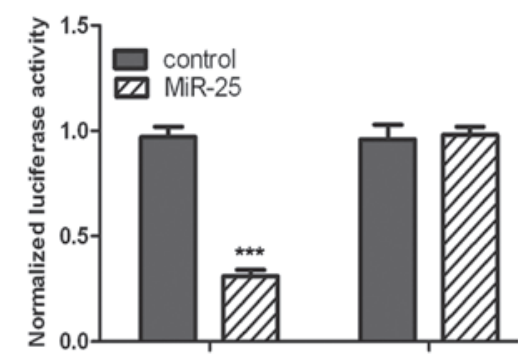

C

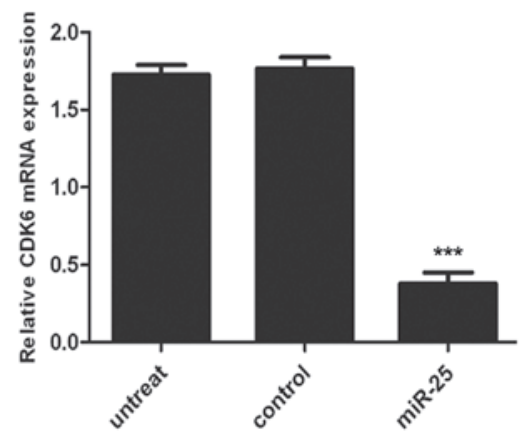

D

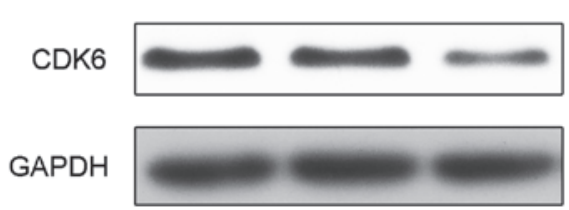

Figure 3. miR-25 directly regulates the CDK6 gene in VSMCs. (A) CDK6 was identified as a potential target of miR-25. CDK6 3'-mut indicates the CDK6 3'-UTRs with six mutation sites (underlined) in miR-25 binding sites. (B) miR-25 mimic but not the control mimic significantly suppressed the luciferase activity of the reporter gene containing WT 3'-untranslated region of CDK6, but did not affect the activity of the gene containing mutant 3'-UTR. (C) Reverse transcription-quantitative polymerase chain reaction analysis demonstrated that overexpression of miR-25 suppressed the mRNA expression of CDK6. (D) Overexpression of miR-25 was observed to inhibit CDK6 protein expression using western blot analysis. GAPDH was also detected as a loading control. ${ }^{* * *} \mathrm{P}<0.001 \mathrm{vs}$. control. miR-25, microRNA-25; CDK6, cyclin-dependent kinase 6; VSMCs, vascular smooth muscle cells; WT, wild type; MUT, mutant; untreat, untreated.

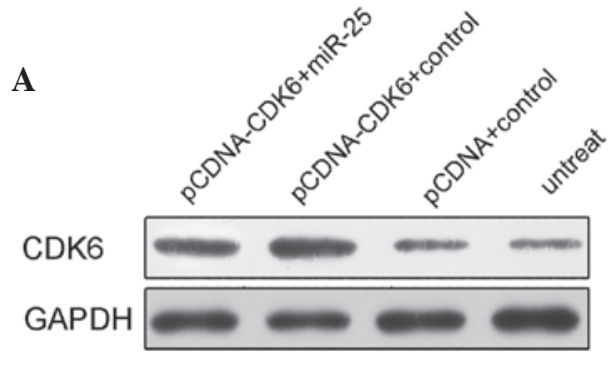

C

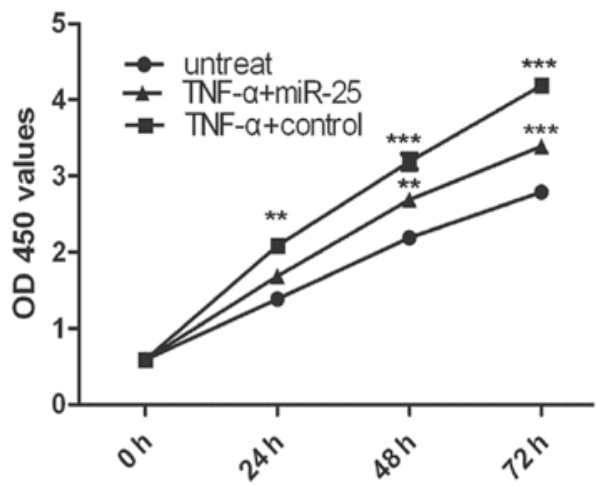

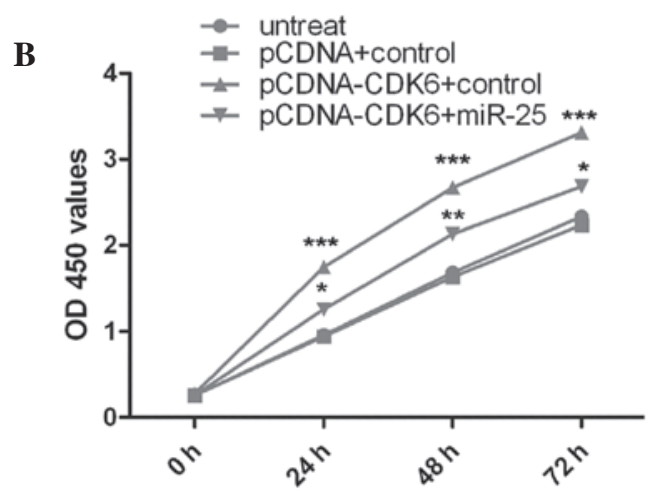

D

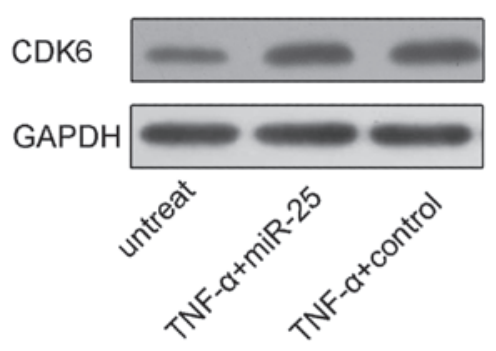

Figure 4. CDK6 is involved in miR-25-mediated proliferation of VSMCs. (A) Western blot analysis of CDK6 expression in untreated VSMCs or those co-transfected with either miR-25 mimics or control with pCDNA-CDK6 or a pCDNA empty vector; GAPDH was also detected as a loading control. (B) Cell growth curves in the VSMCs transfected with different combinations using CCK8 proliferation analysis. (C) CCK8 proliferation analysis demonstrated that the promotion of cell proliferation upon TNF- $\alpha$ stimulation was significantly attenuated by the re-introduction of miR-25. (D) Western blot analysis demonstrated that TNF- $\alpha$ can enhance the CDK6 protein expression and miR-25 can attenuate this effect. GAPDH was also detected as a loading control. ${ }^{*} \mathrm{P}<0.05$, ${ }^{* *} \mathrm{P}<0.01$ and ${ }^{* * *} \mathrm{P}<0.001$, vs. untreated. CDK6, cyclin-dependent kinase 6; miR-25, microRNA-25; VSMCs, vascular smooth muscle cells; CCK8, Cell Counting kit 8; TNF- $\alpha$, tumor necrosis factor- $\alpha$; OD, optical density; untreat, untreated. 
CDK6 is involved in miR-25-mediated VSMC proliferation. To explore whether miR-25 mediated tumor suppression in VSMCs via directly targeting CDK6, a 'rescue' methodology was used. The expression of CDK6 was restored in cells that had been previously treated with miR-25 mimics. In agreement with the restored expression of CDK6 protein (Fig. 4A), an increase in cell proliferation was observed upon transfection with the CDK6 plasmid (Fig. 4B). Furthermore, miR-25 mimics were able to inhibit cell proliferation and the promotion of cell proliferation following TNF- $\alpha$ treatment was significantly attenuated by the re-introduction of miR-25 (Fig. 4C). In addition, TNF- $\alpha$ was able to enhance CDK6 protein expression and miR-25 attenuated this effect (Fig. 4D).

\section{Discussion}

The abnormal proliferation of VSMCs is critical in the pathogenesis of atherosclerosis, coronary heart disease and restenosis $(24,25)$. The presence of chronic or mild inflammation in the arteries is a risk factor for cardiovascular disease $(26,27)$ and TNF- $\alpha$ is a potent inflammatory cytokine. TNF- $\alpha$ has been reported to possess the ability to induce vascular damage and promote the pathogenesis of atherosclerosis $(8,28)$. In addition, TNF- $\alpha$ is known to regulate the proliferation and migration of VSMCs, which results in calcium deposition and an increase in arterial stiffness $(12,29,30)$. However, the precise mechanisms of TNF- $\alpha$ in the regulation of abnormal VSMC proliferation remains to be fully elucidated. The data of the current study suggested that TNF- $\alpha$ inhibits miR-25 expression, overexpression of miR-25 suppresses the proliferation of VSMCs and overexpression of CDK6 impairs the miR-25-induced inhibition of proliferation of VSMCs. These observations suggest that TNF- $\alpha$ may function to promote abnormal proliferation of the VSMCs via the inhibition of miR-25. Thus, miR-25 may be a potential therapeutic target in the treatment of vascular disease.

Previous studies have demonstrated that miR-25 is able to regulate various developmental and cellular processes, and is implicated in a number of human diseases (31-33). miR-25 is known to be important in several types of cancer, including hepatocellular carcinoma, and colon, gastric and lung cancer (34-36). miR-25 has been indicated to be involved in various cellular processes, including cell proliferation, apoptosis and the release of cytokines (37-40). Esposito et al (36) demonstrated that miR-25 was reduced in anaplastic thyroid carcinomas, and ectopic expression of miR-25 suppressed the proliferation and colony formation of anaplastic thyroid carcinoma cells via the induction of $\mathrm{G}_{2} / \mathrm{M}$-phase cell cycle arrest (36). However, the precise function of miR-25 in VSMCs remains unknown. In the present study, TNF- $\alpha$ was observed to inhibit the expression of miR-25. Furthermore, overexpression of miR-25 was suggested to inhibit VSMC proliferation. Thus, it is possible that TNF- $\alpha$ induces VSMC proliferation partly via the inhibition of miR-25 expression.

Various previous studies have suggested that cell proliferation may be caused by dysregulation of cell cycle-associated proteins, including cyclins, CDKs and CDK inhibitors $(41,42)$. CDK6 is a member of the family of serine-threonine kinases, which predominantly mediate the regulation of cell cycle progression (43). The CDK6 gene has been observed to often be amplified or overexpressed in various types of human cancer, including gastric cancer, Ewing's sarcoma and lymphoid malignancies (44-46). A previous study demonstrated that acetylbritannilactone (ABL) treatment inhibited platelet-derived growth factor-induced synthesis and proliferation of DNA in cultured VSMCs. The ABL-mediated inhibition of cell growth was associated with $\mathrm{G}_{1}$ phase arrest. This was correlated with a reduction in expression levels of cyclins D1, A and E, and CDK2, 4 and 6, in addition to an increase in the expression of the CDK inhibitory protein p21cip1 and enhanced binding of p21cip1 to CDKs (47). The current study demonstrated that CDK8 is the target of miR-25 in VSMCs, as transfection of miR-25 resulted in a substantial reduction of luciferase activity by the luciferase expression constructs that carry the target CDK6 fragment compared with the mutant constructs that lack this site. Furthermore, ectopic expression levels of miR-25 significantly downregulated the transcription of the CDK6 gene and the expression of CDK6 protein. Thus, decreased expression of miR-25 in tumor cells is suggested to contribute to the increasing expression levels of CDK6 at the post-transcriptional level and in atherosclerotic progression.

In conclusion, the present study suggests that TNF- $\alpha$ inhibits the expression of miR-25 and overexpression of miR-25 inhibits the proliferation of VSMC via targeting CDK6. These results aid in the understanding of the pro-atherogenic mechanisms of TNF- $\alpha$. miR-25 is suggested to serve an important role in the proliferation of VSMCs and atherosclerosis induced by TNF- $\alpha$. However, in order to further elucidate the precise mechanisms of the TNF- $\alpha$-mediated regulation of VSMC proliferation, further investigation is required.

\section{References}

1. Zeidan A, Purdham DM, Rajapurohitam V, Javadov S, Chakrabarti S and Karmazyn M: Leptin induces vascular smooth muscle cell hypertrophy through angiotensin II- and endothelin-1-dependent mechanisms and mediates stretch-induced hypertrophy. J Pharmacol Exp Ther 315: 1075-1084, 2005.

2. Chen NX, Kiattisunthorn K, O'Neill KD, et al: Decreased microRNA is involved in the vascular remodeling abnormalities in chronic kidney disease (CKD). PloS One 8: e64558, 2013.

3. Davis-Dusenbery $\mathrm{BN}, \mathrm{Wu} \mathrm{C}$ and Hata A: Micromanaging vascular smooth muscle cell differentiation and phenotypic modulation. Arterioscler Thromb Vasc Biol 31: 2370-2377, 2011.

4. Kothapalli D, Castagnino P, Rader DJ, Phillips MC, Lund-Katz S and Assoian RK: Apolipoprotein E-mediated cell cycle arrest linked to p27 and the Cox2-dependent repression of miR221/222. Atherosclerosis 227: 65-71, 2013.

5. Bohlen F, Kratzsch J, Mueller M, et al: Leptin inhibits cell growth of human vascular smooth muscle cells. Vascul Pharmacol 46: 67-71, 2007.

6. Bodary PF, Shen Y, Ohman M, et al: Leptin regulates neointima formation after arterial injury through mechanisms independent of blood pressure and the leptin receptor/STAT3 signaling pathways involved in energy balance. Arterioscler Thromb Vasc Biol 27: 70-76, 2007.

7. Beltowski J: Leptin and atherosclerosis. Atherosclerosis 189: 47-60, 2006.

8. Davis R, Pillai S, Lawrence N, Sebti S and Chellappan SP: TNF- $\alpha$-mediated proliferation of vascular smooth muscle cells involves Raf-1-mediated inactivation of $\mathrm{Rb}$ and transcription of E2F1-regulated genes. Cell Cycle 11: 109-118, 2012.

9. Gao X, Belmadani S, Picchi A, et al: Tumor necrosis factor-alpha induces endothelial dysfunction in Lepr(db) mice. Circulation 115: 245-254, 2007. 
10. Rajesh M, Mukhopadhyay P, Haskó G, Huffman JW, Mackie K and Pacher P: CB2 cannabinoid receptor agonists attenuate TNF-alpha-induced human vascular smooth muscle cell proliferation and migration. Br J Pharmacol 153: 347-357, 2008.

11. Lee SJ, Kim WJ and Moon SK: TNF-alpha regulates vascular smooth muscle cell responses in genetic hypertension. Int Immunopharmacol 9: 837-843, 2009.

12. Rho MC, Ah Lee K, Mi Kim S, et al: Sensitization of vascular smooth muscle cell to TNF-alpha-mediated death in the presence of palmitate. Toxicol Appl Pharmacol 220: 311-319, 2007.

13. Song B, Wang Y, Xi Y, et al: Mechanism of chemoresistance mediated by miR-140 in human osteosarcoma and colon cancer cells. Oncogene 28: 4065-4074, 2009.

14. Yu X, Li Z, Shen J, et al: MicroRNA-10b promotes nucleus pulposus cell proliferation through RhoC-Akt pathway by targeting HOXD10 in intervetebral disc degeneration. PloS One 8: e83080, 2013.

15. Hutcheson R, Terry R, Chaplin J, et al: MicroRNA-145 restores contractile vascular smooth muscle phenotype and coronary collateral growth in the metabolic syndrome. Arterioscler Thromb Vasc Biol 33: 727-736, 2013.

16. Martello G, Rosato A, Ferrari F, et al: A MicroRNA targeting dicer for metastasis control. Cell 141: 1195-1207, 2010.

17. Majid S, Dar AA, Saini S, et al: MicroRNA-23b functions as a tumor suppressor by regulating Zeb1 in bladder cancer. PloS One 8: e67686, 2013.

18. Wu WK, Lee CW, Cho CH, et al: MicroRNA dysregulation in gastric cancer: a new player enters the game. Oncogene 29: 5761-5771, 2010

19. Brenner B, Hoshen MB, Purim O, et al: MicroRNAs as a potential prognostic factor in gastric cancer. World J Gastroenterol 17: 3976-3985, 2011

20. Cullen BR: MicroRNAs as mediators of viral evasion of the immune system. Nat Immunol 14: 205-210, 2013.

21. Rotllan N and Fernández-Hernando C: MicroRNA regulation of cholesterol metabolism. Cholesterol 2012: 847849, 2012.

22. Chen KC and Juo SH: MicroRNAs in atherosclerosis. Kaohsiung J Med Sci 28: 631-640, 2012.

23. Chen LJ,Lim SH, Yeh YT, Lien SC and Chiu JJ: Roles of microRNAs in atherosclerosis and restenosis. J Biomed Sci 19: 79, 2012.

24. Sun Y, Chen D, Cao L, et al: MiR-490-3p modulates the proliferation of vascular smooth muscle cells induced by ox-LDL through targeting PAPP-A. Cardiovasc Res 100: 272-279, 2013.

25. Yu ML, Wang JF, Wang GK, et al: Vascular smooth muscle cell proliferation is influenced by let-7d microRNA and its interaction with KRAS. Circ J 75: 703-709, 2011.

26. Kim S and Kang H: miR-15b induced by platelet-derived growth factor signaling is required for vascular smooth muscle cell proliferation. BMB Rep 46: 550-554, 2013.

27. Li P, Liu Y, Yi B, et al: MicroRNA-638 is highly expressed in human vascular smooth muscle cells and inhibits PDGF-BB-induced cell proliferation and migration through targeting orphan nuclear receptor NOR1. Cardiovasc Res 99: 185-193, 2013.

28. Gómez-Hernández A, Escribano Ó, Perdomo L, et al: Implication of insulin receptor A isoform and IRA/IGF-IR hybrid receptors in the aortic vascular smooth muscle cell proliferation: role of TNF- $\alpha$ and IGF-II. Endocrinology 154: 2352-2364, 2013.

29. Jiang F, Jiang R, Zhu X, Zhang X and Zhan Z: Genipin inhibits TNF- $\alpha$-induced vascular smooth muscle cell proliferation and migration via induction of HO-1. PloS One 8: e74826, 2013.
30. Kim HH and Kim K: Enhancement of TNF-alpha-mediated cell death in vascular smooth muscle cells through cytochrome c-independent pathway by the proteasome inhibitor. FEBS Lett 535: 190-194, 2003.

31. Li Q, Zou C, Han Z, et al: MicroRNA-25 functions as a potential tumor suppressor in colon cancer by targeting Smad7. Cancer Lett 335: 168-174, 2013.

32. Razumilava N, Bronk SF, Smoot RL, et al: miR-25 targets TNF-related apoptosis inducing ligand (TRAIL) death receptor-4 and promotes apoptosis resistance in cholangiocarcinoma. Hepatology 55: 465-475, 2012.

33. Lu D, Davis MP, Abreu-Goodger C, et al: MiR-25 regulates Wwp2 and Fbxw7 and promotes reprogramming of mouse fibroblast cells to iPSCs. PloS One 7: e40938, 2012.

34. Su ZX, Zhao J, Rong ZH, Geng WM, Wu YG and Qin CK: Upregulation of microRNA-25 associates with prognosis in hepatocellular carcinoma. Diagn Pathol 9: 47, 2014.

35. Xu FX, Su YL, Zhang H, Kong JY, Yu H and Qian BY: Prognostic implications for high expression of MiR-25 in lung adenocarcinomas of female non-smokers. Asian Pac J Cancer Prev 15: 1197-1203, 2014.

36. Esposito F, Tornincasa M, Pallante P, et al: Down-regulation of the miR-25 and miR-30d contributes to the development of anaplastic thyroid carcinoma targeting the polycomb protein EZH2. J Clin Endocrinol Metab 97: E710-E718, 2012

37. Li X, Yang C, Wang X, Zhang J, Zhang R and Liu R: The expression of miR-25 is increased in colorectal cancer and is associated with patient prognosis. Med Oncol 31: 781, 2014.

38. Wahlquist C, Jeong D, Rojas-Muñoz A, et al: Inhibition of miR-25 improves cardiac contractility in the failing heart. Nature 508: 531-535, 2014.

39. Setyowati Karolina D, Sepramaniam S, Tan HZ, Armugam A and Jeyaseelan K: miR-25 and miR-92a regulate insulin I biosynthesis in rats. RNA Biol 10: 1365-1378, 2013.

40. Zhang H, Zuo Z, Lu X, Wang L, Wang H and Zhu Z: MiR-25 regulates apoptosis by targeting Bim in human ovarian cancer. Oncol Rep 27: 594-598, 2012.

41. Grossel MJ and Hinds PW: Beyond the cell cycle: a new role for Cdk6 in differentiation. J Cell Biochem 97: 485-493, 2006.

42. Pauls E, Ruiz A, Badia R, et al: Cell cycle control and HIV-1 susceptibility are linked by CDK6-dependent CDK2 phosphorylation of SAMHD1 in myeloid and lymphoid cells. J Immunol 193: 1988-1997, 2014.

43. Kohrt D, Crary J, Zimmer M, et al: CDK6 binds and promotes the degradation of the EYA2 protein. Cell Cycle 13: 62-71, 2014.

44. Wu J, Qian J, Li C, et al: miR-129 regulates cell proliferation by downregulating Cdk6 expression. Cell Cycle 9: 1809-1818, 2010.

45. Dauphinot L, De Oliveira C, Melot T, et al: Analysis of the expression of cell cycle regulators in Ewing cell lines: EWS-FLI-1 modulates p57KIP2and c-Myc expression. Oncogene 20: 3258-3265, 2001.

46. Kollmann K and Sexl V: CDK6 and p16INK4A in lymphoid malignancies. Oncotarget 4: 1858-1859, 2013.

47. Liu B, Han M, Sun RH, Wang JJ, Liu YP and Wen JK: Acetylbritannilactone induces G1 arrest and apoptosis in vascular smooth muscle cells. Int J Cardiol 149: 30-38, 2011. 